\title{
APREENDENDO À CIDADANIA: \\ EXTENSÃO UNIVERSITÁRIA E DIREITOS HUMANOS
}

\section{Marina Soares Vital Borges}

Titulação Acadêmica: Mestranda em Direito,

Área Direito, Estado e Sociedade, Subárea Sistema de Justiça Vínculo Institucional: Universidade Federal de Santa Catarina

e-mail: marina_vital@yahoo.com.br

RESUMO: O presente artigo pretende contribuir com as discussões sobre a importância da extensão universitária nas faculdades de direito e os benefícios que tais projetos podem trazer para as comunidades de baixa renda envolvidas e para a universidade, uma vez que promovem a imprescindível integração do conhecimento com a prática. Apresentando as atividades e dinâmicas realizadas no Projeto "Apreendendo à Cidadania", da Faculdade de Direito da Universidade Federal de Santa Catarina, o artigo colabora também com uma proposta de um ensinoaprendizagem do direito de forma menos dogmática e excludente. Com os resultados obtidos nesse projeto, o artigo procura despertar para a importância de se ensinar direitos humanos nas comunidades carentes, e ao mesmo tempo se dispor a aprender com os atores envolvidos, construindo conjuntamente propostas para a efetiva construção da cidadania.

PALAVRAS-CHAVE: Cidadania; Direitos; Humanos; Extensão. 


\section{INTRODUÇÃO}

O artigo pretende relatar experiências adquiridas no projeto "Apreendendo à Cidadania", coordenado pela Prof. ${ }^{a}$ Dr ${ }^{a}$ Thaís Luzia Colaço, na Faculdade de Direito da Universidade Federal de Santa Catarina, envolvendo alunos da graduação e pósgraduação.

A autora deste artigo participa ativamente deste projeto, cooperando com os encontros em uma das escolas participantes, auxiliando na confecção de projetos que visam angariar recursos para 0 projeto, tendo atuado também, até 0 ano passado, como coordenadora dos trabalhos da Escola Estadual Básica Getúlio Vargas.

O projeto pretende ser um elo entre os universitários participantes e a sociedade, através de atividades de Extensão. Este vínculo é realizado em um processo educativo, cultural e científico que trabalha o ensino e a pesquisa de forma indissociável.

É um aprendizado mútuo, onde o acadêmico e a comunidade se relacionam de forma democrática. Esse estreitamento dos laços de atuação entre o meio universitário e a comunidade, promovendo efetivo intercâmbio entre o saber teórico e o senso prático, tem produzido grandes resultados, os quais pretende-se apresentar aqui.

\section{IMPORTÂNCIA DA EXTENSÃO UNIVERSITÁRIA}

A aprendizagem universitária, nos moldes que se tem hoje, está edificada somente no ensino, e este se faz de forma extremamente tecnicista, visando apenas a formar "juristas", deixando de lado a pesquisa e a extensão. O projeto parte da premissa que o ensino de noções jurídicas, vinculado à realização de dinâmicas e vivências junto a uma comunidade pode produzir conhecimento, promovendo um aprendizado muito mais consciente e emancipatório.

Já é tempo dos estudantes de direito despertarem para a realização de um ensino que supere aquela a dogmática tecnicista, a reprodução acrítica de uma cultura jurídica dominante, que é a característica da imensa maioria das faculdades 
de direito em nosso país. Vejamos as contribuições de Miguel Pressburger ${ }^{1}$ (citado por Faria, 1992, p.128-129):

No Instituto, nós achamos que os advogados e outros doutores só tem dois caminhos nas suas profissões: um deles é emprestar seu conhecimento para os movimentos populares e não ficar separado deles; pelo contrário, estar firmemente junto nas lutas pelas transformações da sociedade: o outro caminho é ficar "na sua", isto é, mesmo tendo simpatia pelo povo, "cuidar de sua vida" numa posição individualista. Essa posição é conservadora: ajuda as forças que não querem mudanças na sociedade, forças que pretendem conservar tudo como está. Um advogado que nunca viu os operários na fábrica, nunca foi ao campo saber como o lavrador dá duro de sol a sol, nunca subiu o morro e conheceu a situação dos favelados, não consegue imaginar o que as pessoas simples pensam sobre o Direito e a Justiça. Só fica sabendo aquilo que os professores ensinam na escola, aquilo que o juiz acha lá no tribunal, aquilo que os colegas discutem nos escritórios. Mas, nem o professor, nem o juiz e nem a maioria dos colegas conheceu uma fábrica por dentro, foi a roça, ou subiu à favela. Por isso o Direito e a Justiça podem parecer uma coisa para o pessoal que vive no mundo das salas de audiência, dos cartórios, dos corredores do fórum; e parecer outra coisa para o povo, que nem conhece aquele mundo. [grifo nosso]

Por outro lado, os benefícios não são apenas para os estudantes, pois integrando as dificuldades, informações e demandas daquela parcela da sociedade, pode-se revitalizar o conhecimento asséptico produzido na academia, dando suporte à uma ação social concreta na comunidade envolvida.

O projeto pretende viabilizar, por intermédio da educação, o acesso ao conhecimento pela população carente de seus direitos e deveres de cidadão, amenizando as desigualdades sociais que continuam se perpetuando à população menos favorecida economicamente.

Além disso, os estudantes que têm contato com o Projeto são estimulados a serem difusores das idéias elaboradas levando-as ao convívio da família, grupo de amigos, etc.

Vale lembrar que o espírito do projeto não é o de levar o conhecimento para a comunidade, não se realiza "palestras" sobre direitos nas escolas. Nossos encontros são caracterizados pela informalidade, pela aproximação do direito apresentado à realidade da comunidade, e por uma disposição dos universitários a efetuar trocas com a comunidade. Tudo isso gerido uma metodologia não diretiva de

\footnotetext{
${ }^{1}$ Miguel Pressburger, o Direito, a Justiça e a Lei, apresentação IAPJ em co-edição com a Federação de
} 
ensino, onde as "aulas" são dialogadas e os instrutores e participantes estão no mesmo patamar. (BECKER, 1994, p. 88)

Somente partindo da premissa de que a comunidade também tem algo a contribuir para o aprendizado dessa cidadania, é que se pode obter resultados efetivamente transformadores e emancipatórios. Ou, conforme nos ensina Freire (1981), estar-se-á deixando de lado a "educação bancária" - entendendo-se esta como se os alunos fossem um banco, no qual o professor faz o depósito e os alunos o recebem, arquivando-o, até a chegada da prova, ocasião em que o professor vem buscar o extrato memorizado de seu depósito - para um ensino de construção do conhecimento, em que a pesquisa científica e a formação da cidadania estão a todo o momento presentes.

Uma capacitação interdisciplinar vêm sendo buscada continuamente, para que se possa efetuar uma inserção nas comunidades de forma aberta e solidária, e não com o intuito de levar a "nossa idéia de cidadania" até eles. O intuito do projeto se coaduna muito com, novamente, as idéia de Freire (1997, p.25)

É preciso que [...] desde os começos do processo, vá ficando cada vez mais claro que, embora diferentes entre si, quem forma se forma e re-forma ao formar e quem é formado forma-se e forma ao ser formado. É neste sentido que ensinar não é transferir conhecimentos, conteúdos, nem formar é ação pela qual um sujeito criador dá forma, estilo ou alma a um corpo indeciso e acomodado. Não há docência sem discência, as duas se explicam e seus sujeitos, apesar das diferenças que os conotam, não se reduzem à condição de objeto um do outro. Quem ensina aprende ao ensinar e quem aprende ensina ao aprender. [grifo nosso]

O que se pretende é promover a integração entre conhecimento e prática, entre universidade e a comunidade, produzindo propostas conjugadas de pensar o direito de forma menos tecnicista e dogmática.

\section{CIDADANIA E DIREITOS HUMANOS}

Para atingir os objetivos acima apontados, o grupo utiliza uma visão ampla do conceito de cidadania, pois os trabalhos são realizados com temáticas que sejam de interesse da comunidade, e que possam ser abarcadas dentro do conceito de cidadania como exercício dos direitos humanos. 
O termo cidadania é muito antigo, mas sua discussão permanece inacabada, assumindo um caráter contemporâneo, uma vez que se luta permanentemente pela manutenção de direitos adquiridos e pela garantia de novos direitos. A constituição de 1988, erigiu a dignidade da pessoa humana a princípio fundamental (art. 1..., III), instituindo um novo valor que confere suporte a todo o sistema jurídico e que deve ser considerado quando se trata de interpretar qualquer das normas constantes do ordenamento nacional.

Dentre os limites deste artigo, não se pretende aprofundar sobre o conceito de cidadania, nem sobre essa proximidade entre cidadania e direitos humanos, tecendo apenas alguns comentários a título de suporte para apresentação dos dados sobre o projeto realizado.

Ser cidadão é ter direitos e deveres. Segundo Manzini-Crove (1991, p.9) Tal situação está descrita na Carta de Direitos da Organização das nações Unidas (ONU), 1948. A proposta principal de cidadania contida nesta Carta é de que:

[...] todos os homens são iguais ainda que perante a lei, sem discriminação de raça, credo ou cor. E ainda: a todos cabem o domínio sobre seu corpo e sua vida, o acesso a um salário condizente para promover a própria vida, o direito à educação, à saúde, à habitação, ao lazer, o direito de poder se expressar livremente, militar em partidos políticos e sindicatos, fomentar movimentos sociais, lutar por seus valores. Enfim o direito de uma vida digna de ser homem.

A autora continua destacando que o cidadão também deve ter deveres:

[..] ser o próprio fomentador da existência dos direitos a todos, ter responsabilidade em conjunto pela coletividade, cumprir as normas e propostas elaboradas e decididas coletivamente, fazer parte do governo, direta ou indiretamente, ao votar, ao pressionar através dos movimentos sociais, ao participar de assembléias - no bairro, sindicato, partido ou escola. (MANZINI-CROVE, 1991, p.9)

Este conceito revela a amplitude de temas possíveis de serem tratados e a proximidade dos mesmos com a educação para os direitos humanos. Vale lembrar que o conteúdo da cidadania apresentado só existirá se houver a prática da reivindicação, ela deve ser a estratégia para a construção de uma sociedade melhor. As próprias pessoas devem ser os agentes da existência desses direitos (MANZINICROVE, 1991, p.9). E a única forma que as pessoas têm de se transformar nesses 
agentes desses direitos é a educação emancipatória, que promove conscientização e instiga a mobilização social.

O contexto da sociedade brasileira contemporânea, segundo Andrade (1993, p.129) evidencia, que para além de uma cidadania individual, há demandas por construções coletivas da cidadania ao mesmo tempo em que, para além da representação política, a cidadania aponta para a participação em sentido amplo através da evidente politização. O horizonte de possibilidades da cidadania, na sociedade brasileira extrapola os limites da cidadania liberal, desafiando seus próprios pressupostos.

Assim sendo, a noção de cidadania identifica-se hoje perfeitamente com a idéia de Direitos Humanos. Um cidadão somente será considerado como tal se possuir o exercício de seus Direitos Humanos, constitucional e legalmente garantidos. Cidadão é aquele que não apenas vota, mas tem conhecimento de seus direitos e instrumentos para participar da construção da sociedade.

\section{PROJETO APREENDENDO A CIDADANIA}

O Projeto "Apreendendo à Cidadania" existe desde Março de 2004, tendo como objetivo geral viabilizar, através de encontros realizados em escolas interessadas da rede pública da cidade de Florianópolis, o acesso ao conhecimento a direitos e deveres de cidadão, ajudando a amenizar as desigualdades sociais, instigando uma maior participação política e trabalhando também com a auto-estima dessas crianças e adolescentes, muitas vezes já inseridos na realidade da violência e da criminalidade.

Envolvendo cerca de 25 (vinte e cinco) alunos do curso de Direito, realiza-se um trabalho voluntário de conscientização de crianças e adolescentes carentes e em situação de risco de exclusão social, sobre a noção de cidadania, os direitos sociais básicos do cidadão, direitos políticos, direito à saúde, direito do consumidor, direito penal, direito do trabalho e direito da criança e do adolescente.

Como objetivos específicos do estudo, pode-se destacar:

- Proporcionar à universidade pública a oportunidade de realizar a sua função social como instrumento da superação da exclusão social e da promoção da cidadania. 
- Facilitar a melhoria da qualidade de vida dos segmentos excluídos, pelo conhecimento de seus direitos de cidadãos e a melhoria de sua autoestima.

- Produzir conhecimento teórico referente às categorias: cidadania e educação.

O projeto possui alguns princípios básicos que, junto com os objetivos, regulam suas atividades, dentre eles pode-se apontar o não-assistencialismo, uma vez que o trabalho não busca oferecer assistência jurídica ${ }^{2}$ às comunidades, limitando-se a oferecer informações e encaminhar as pessoas que tenham necessidade de assistência jurídica aos órgãos competentes. Além disso, essa postura não-assistencialista, denota um repúdio a dependência, ou hierarquia, que é criada entre comunidade e universitários, em tantos outros projetos onde a universidade visa atender a comunidade carente $^{3}$. O que se pretende é que a comunidade se liberte desse papel de "assistido" e seja protagonista na efetivação de seus Direitos. O projeto pauta-se no tripé da aprendizagem universitária (ensino, pesquisa e extensão) de forma indissociável, onde, para que se possa realizar uma atividade numa comunidade (extensão), é preciso proceder previamente um estudo de sua realidade, suas demandas e buscar alternativas (pesquisa); e por fim promove-se uma capacitação com os universitários envolvidos (ensino) para realização do trabalho de conscientização e mobilização social.

Outro ponto fundamental que orienta o trabalho é a interdisciplinaridade. $O$ projeto conta com a colaboração de alguns alunos de outras Faculdades (Serviço Social e Jornalismo), mas além disso, o que vêm se buscando é a utilização de técnicas metodológicas e subsídios sobre direitos humanos, política, sociologia, pedagogia infantil, trabalho com comunidades carentes, e outros; oriundos das mais diversas áreas do conhecimento, na tentativa, de relacionando-as com o direito, atender cada vez mais as necessidades das comunidades envolvidas.

\footnotetext{
2 Para um debate sobre assistência e assessoria, veja ALFONSIM (1998) e LUZ (2005)

3 Dentre esses projetos, pode-se citar os diversos Escritórios - Modelo de Assistência Jurídica existentes em nossas faculdades de Direitos em todo o país, que apesar de muitas vezes prestarem um serviço ao cidadão não funcionam como agentes de mobilização popular na luta pela efetivação de seus direitos.
} 


\subsection{Resultados alcançados e perspectivas de crescimento}

O projeto realizado no ano de 2004 previu inicialmente a escolha entre várias escolas públicas de ensino, aquelas que tivessem interesse em participar do projeto. O resultado apontou as seguintes escolas: Escola Estadual Básica Padre Anchieta, Escola Estadual Américo Dutra Machado e Escola Estadual Básica Getúlio Vargas.

Após a escolha das escolas participantes, foram selecionados os alunos do curso de Direito da Universidade Federal de Santa Catarina, bem como alunos da Pós-Graduação que tivessem interesse em desenvolver este tipo de trabalho. A seguir, foram compostos 03 (três) grupos, que realizaram a primeira abordagem nas escolas escolhidas buscando identificar as carências dos alunos em relação ao conhecimento e ao entendimento dos direitos dos cidadãos.

Os universitários foram encarregados de desenvolver, cada um, quatro horas de atividade semanal no âmbito da escola, sendo que as temáticas dos seminários, grupos de discussão e oficinas são independentes em cada escola trabalhada, haja vista a diversidade do público alvo (a faixa etária oscila entre crianças de nove anos até indivíduos adultos) e o interesse de cada turma envolvida.

Antes que se analise algumas dinâmicas interessantes para o ensino dos direitos humanos, é importante que se faça uma breve caracterização de cada escola a fim de que se tenha claro o público alvo que o projeto têm atingido:

a) A Escola Estadual Básica Padre Anchieta, localizada no Bairro Agronômica, recebe muitos alunos provenientes das Favelas do Maciço do Morro da Cruz, tais como Morro do Horácio, Morro do Nova Trento, Morro do 25 e Morro do Checa-Checa.. São freqüentes os relatos de alunos envolvidos com tráfico de drogas, furtos, gangues, porte de armas, violência doméstica e mesmo sexual. A escola recebe, ainda, alunos abrigados em Casas-lares de adoção, como o Lar Recanto do Carinho que atende crianças portadoras de HIV.

Os universitários trabalham nesta escola com as $3^{\mathrm{a}}$ e $4^{\mathrm{a}}$ séries, abarcando cerca de 250 crianças, no período de setembro à novembro de 2004. No ano de 2005, trabalhou-se com cerca de 200 crianças, no período que se iniciou em abril e finalizará em novembro. $\mathrm{O}$ Grupo conta com 14 universitários trabalhando na escola. 
b) A Escola Estadual Américo Dutra Machado encontra-se no Bairro Monte Cristo, e divide as favelas de Novo Horizonte e de Chico Mendes. As principais demandas sociais às quais o Projeto visam atender nesta escola são, em primeiro lugar, o combate ao tráfico de drogas no sentido de prevenir o envolvimento de crianças e adolescentes; e num segundo plano prevenir a violência entre os alunos, fomentada pela rivalidade que existe entre os estudantes provenientes das duas favelas vizinhas à escola. Vários episódios de conflitos entre gangues provenientes das favelas já foram verificadas na escola. Nesta escola, apenas duas turmas ( $7^{\mathrm{a}} \mathrm{e}$ $8^{\text {a }}$ série) do ensino fundamental, participam do projeto. É uma escola pequena, mas de grande importância na consecução dos objetivos do nosso projeto.

c) A Escola Getúlio Vargas está localizada no Bairro Saco dos Limões, uma região relativamente tranqüila, comparada a realidade das outras escolas participantes no projeto. A Escola não atende a uma comunidade específica, recebendo alunos de diversas áreas da cidade. Em geral, a problemática relacionada à violência não é percebida de forma tão evidente e não há uma realidade generalizada de potencial envolvimento de crianças e adolescentes com o tráfico de drogas, como nos institutos mencionados anteriormente. Todavia, isto não significa que tais problemas não existem: a escola também agrega alunos vindos da favela Morro da Caieira, que fica nas proximidades.

Contando com cerca de três mil alunos e um corpo docente de 85 professores, atendendo do $1^{\circ}$ ano do ensino fundamental até o magistério, a escola, como outras grandes escolas, sofre de diversas carências, físicas, didáticas e pedagógicas. No ano de 2004, quando se iniciaram as atividades do projeto o público alvo foi os alunos de $1^{\circ}$ e $2^{\circ}$ anos do Ensino Médio e o Magistério, contabilizando assim 20 turmas. Ao final das atividades do ano de 2004, constatouse que cerca de 500 adolescentes foram envolvidos pelo projeto, no período de setembro a dezembro de $2004^{4}$. No ano de 2005, por determinação da escola, o projeto abrangerá apenas 10 turmas ( $2^{\circ}$ ano do Ensino Médio), atingindo cerca de 250 crianças, no período que se iniciou em abril e finalizará em novembro. O Grupo conta com 9 estudantes universitários trabalhando nesta escola.

\footnotetext{
${ }^{4}$ O período de março a setembro de 2004, o grupo não promoveu encontros tendo sido um período de escolha e capacitação dos universitários.
} 
Além das atividades nas escolas, no ano de 2005, buscou-se uma parceria com uma organização não-governamental chamada Balakubatuki, Arte e Cidadania. Fundada em 1998, por Daniel Cirimbelli da Luz, percussionista e arte-educador, o projeto musical visa à educação de crianças em risco social, e é realizado na Casa da Liberdade e na Casa da Criança (casas de apoio a crianças e adolescentes carentes da cidade de Florianópolis). Atualmente, o Projeto atende às seguintes comunidades na grande Florianópolis: Morro da Queimada, Morro do 25, Morro da Caixa, Mocotó, Mont Serrat (Casa da Liberdade), e Morro da Penitenciária (Casa da Criança) e Maciço da Agronômica (Ilha da Criança). São oferecidas aulas de percussão, violão e canto, para crianças de 07 a 14 anos, divididas em turmas conforme a faixa etária.

A união dos dois projetos busca uma otimização dos trabalhos de cada um. Esse intercâmbio iniciou-se em abril do corrente ano, realizando-se apenas encontros quinzenais com os monitores ${ }^{5}$. Nosso objetivo é que os monitores possam se tornar multiplicadores do conhecimento dentro do próprio Balakubatuki, e em suas comunidades, e posteriormente pretende-se estender as atividades para todas as crianças envolvidas.

A abordagem metodológica utilizada em todas as escolas não foi algo dado e imposto à comunidade, ela vêm sendo enriquecida na medida em que o trabalho tem sido efetuado dentro das escolas, uma vez que os universitários empreendem esforços para que os encontros sejam cada vez mais atrativos às crianças e adolescentes.

As atividades lúdicas - jogos, músicas, dinâmicas, expressões artísticas de uma forma geral - que estimulam a participação e criam um ambiente de cumplicidade, fazem parte da metodologia escolhida, aumentando a aceitação e o interesse dos alunos. É um meio eficaz no fortalecimento das relações entre os universitários e a comunidade, pois valoriza a cooperação dos alunos na construção daquele conhecimento pretendido.

Dentro do interesse temático despertado pelos alunos, e no intuito de incentivar a maior participação dos mesmos, realizou-se diversas atividades

\footnotetext{
${ }^{5}$ São considerados monitores, adolescentes que continuam envolvidos com o projeto Balakubatuki, mas que já ultrapassaram a idade de 14 anos, o que os retiraria da faixa etária de atuação das casas de apoio. Esses monitores desenvolvem atividades de auxílio aos professores de música permitindo que os mesmos continuem sendo beneficiados pelas atividades do projeto.
} 
envolvendo o ensino dos direitos humanos e da cidadania de uma forma geral, das quais pode-se destacar:

1- Dentro da Temática Participação Política, os alunos foram incentivados a escrever cartas às autoridades (Prefeito, Governador, Vereadores e Outros) reivindicando melhorias para a sua comunidade. O Objetivo foi propiciar-lhes um exercício de cidadania, onde eles pudessem visualizar a autoridade como algo mais acessível, cuja conduta deve ser monitorada pelo cidadão participativo.

Atividades realizada pela equipe da Escola Estadual GetúlioVargas

Resultados: As cartas foram encaminhadas para as autoridades competentes e estamos aguardando respostas, para trabalharmos com os alunos sobre as possibilidades de efetivação das reivindicações feitas. È interessantíssimo observar, o número de reivindicações feitas e o nível razoável de conscientização política dos estudantes.

2 - Dentro da Temática, Acesso à Justiça, foi realizada uma audiência simulada, buscando esclarecer de forma simples e prática as funções dos agentes do processo, conhecer as noções do procedimento judicial, ressaltando a importância do judiciário para a solução de conflitos e relembrar os órgãos de defensoria dativa. A audiência tratava de um caso hipotético de reconhecimento e dissolução de uma união estável, fixação de guarda e alimentos, onde os "personagens" (juiz, promotor, advogados e etc) foram ocupados pelos próprios alunos.

Atividades realizada pela equipe da escola GetúlioVargas

Resultados: Com essa dinâmica pretende-se desmistificar o papel de cada autoridade ali representada, esclarecendo e fixando as funções que cada um deve exercer. Todas as questões do senso comum que envolvem a caracterização das autoridades são discutidas, e na medida em que a "audiência" vai se realizando os estudantes se mostram mais envolvidos e participativos. Muitas dúvidas sobre a responsabilidade de cada pai na pensão alimentícia e na distribuição dos bens também são discutidas.

3- Procurando discutir com crianças de 9 e 10 anos sobre o direito à saúde, utilizou-se panfletos conseguidos na Vigilância epidemiológica como material de apoio, inclusive sobre a Dengue e a relação de vacinas que cada criança deve tomar gratuitamente nos postos de saúde. Após essa atividade, cada aluno elaborou uma 
história, que foi utilizada pela disciplina de Português, escolhendo uma parte do corpo e descrevendo o que acontece se ela não recebe os cuidados de higiene básicos.

Atividades realizadas pela equipe da Escola Estadual Básica Padre Anchieta

Resultados: A questão da saúde foi tratada de forma lúdica, com crianças de até 10 anos de idade e iniciou-se um processo de conscientização da importância da higiene para a saúde deles. Discutiu-se também sobre a questão do direito que toda pessoa tem de ser atendida no sistema de saúde pública.

4- Dentro da temática de Participação Política, realizou-se durante o período eleitoral de 2004, uma eleição simulada dentro das salas, a fim de elegerem o "Prefeito do Colégio", sendo que os candidatos deveriam apresentar propostas em um debate. Foram discutidas questões sobre a compra de votos e as promessas que não são cumpridas pelas autoridades eleitas, estimulando dessa forma o repasse desses preceitos aos pais que iriam exercer o direito de voto nas eleições para prefeito e vereadores na cidade de Florianópolis.

Atividades realizada pela equipe da Escola Estadual Américo Dutra Machado

Resultados: Os alunos se mostraram muito empenhados na realização da dinâmica, durante os discursos e mesmos durante 0 voto realizado com urna eletrônica.

5- Dentro da temática do Sistema Penal, foi realizado um Júri Simulado, onde a tarefa dos alunos era se dividir em três grupos, (Juiz, Ministério Público e Defesa), e submeter os réus, que na ocasião eram os acadêmicos de direito, ao julgamento.

Atividades realizada pela equipe da Escola Estadual Américo Dutra Machado

Resultados: Os alunos se mostraram muito empenhados na realização da dinâmica, durante as falas de cada autoridade representada por eles. Questionou-se também o Tribunal do Júri em si, se esse mecanismo era o mais adequado para solucionar aquele conflito

As atividades causaram um impacto positivo nas escolas, despertando 0 interesse de alunos e professores. Os universitários continuam motivados e interessados no estudo, pois a cada encontro com os alunos, se renova os objetivos 
pelos quais o projeto se instituiu - a crença de que o ensino de noções de cidadania e direito pode ser útil para a vida daquela comunidade e que as crianças e adolescentes são potenciais difusores desses conhecimentos.

Algumas dificuldades foram encontradas, como a falta de planejamento de algumas escolas no cumprimento dos horários combinados com as escolas, a resistência de alguns alunos que não querem participar das atividades do projeto. Entretanto estes contratempos esporádicos não desmotivam o grupo, uma vez que a grande maioria dos estudantes participa ativamente das dinâmicas propostas, revelando satisfação com os ensinamentos construídos.

No que concerne às atividades, o Projeto pretende, no ano de 2005, buscar financiamentos para continuação do processo de conscientização e formação junto às escolas públicas já beneficiadas. Pretende-se também uma expansão do número de universitários, inclusive englobando outros cursos, com uma ampliação do número de turmas envolvidas e, conseqüentemente, de alunos beneficiados.

\section{CONSIDERAÇÕES FINAIS}

O presente artigo não traz fórmulas prontas e nem respostas acabadas para a problemática da construção da cidadania através do ensino dos direitos humanos. Não se pretende esgotar a discussão, ao contrário, objetiva-se apenas apresentar alguns resultados positivos num projeto de extensão universitária realizado pela Faculdade de Direito da Universidade Federal de Santa Catarina.

Ainda são muitos os desafios para a construção de projetos de extensão universitária realmente emancipatórios e muito há para se escrever sobre um tipo de extensão que efetivamente propicie a integração efetiva entre a teoria e a prática, sem que a comunidade seja vista como um "laboratório" pela universidade.

O projeto "Apreendendo à Cidadania" ainda está em construção e possui suas falhas e limitações. Ao apresentar esses dados, pretendeu-se contribuir com as discussões sobre a importância da extensão universitária nas faculdades de direito e os benefícios que tais projetos podem trazer para as comunidades de baixa renda envolvidas. 
Apresentando as atividades e dinâmicas realizadas, o artigo pretendeu também colaborar com uma proposta de um ensino-aprendizagem do direito de forma menos dogmática e excludente.

O mais importante é esse processo de aproximação da comunidade com a academia, e a consciência de que se ensinar direitos humanos nas comunidades carentes, é ao mesmo tempo se dispor a aprender com os atores envolvidos, construindo conjuntamente propostas para a efetiva construção da cidadania.

\section{BIBLIOGRAFIA}

ALFONSIN, Jacques Távora. Assessoria Jurídica Popular: breve apontamento sobre sua necessidade, limites e perspectivas. Resumo da contribuição do autor ao IV Encontro Internacional de Direito Alternativo, realizado em Florianópolis, entre 15 e 18 de outubro de 1998, sob o tema "Direito e direitos: Democracia, Constituição e Multiculturalismo."

ANDRADE, Vera Regina Pereira de. Cidadania: do direito aos direitos humanos. São Paulo: Acadêmica, 1993.

BECKER, Fernando. Modelos pedagógicos e modelos epistemológicos. Educação e realidade, Porto Alegre: UFRS, v. 19, n. 1, jan./jun. 1993. p. 89-96.

CASTRO JR., Osvaldo Agripino de. A cidadania brasileira e o papel dos operadores do direito na busca de sua consolidação. In: DAL RI JÚNIOR, Arno; OLIVEIRA, Odete Maria de. (Org.). Cidadania e nacionalidade: efeitos e perspectivas: nacionais - regionais - globais. 2 ed. ljuí:Unijuí, 2003.

FARIA, José Eduardo. Justiça e conflito: os juízes em face dos novos movimento sociais. 2. ed. São Paulo: Revista dos Tribunais, 1992,

FREIRE, Paulo. Pedagogia do oprimido. 10ª .ed. Rio de Janeiro: Paz e Terra, 1981.

Pedagogia da autonomia. São Paulo: Paz e Terra, 1997

LUZ, Vladimir de Carvalho. Assessoria Jurídica Popular no Brasil. Dissertação (Mestrado em Direito) - Pós Graduação em Direito da Universidade Federal de Santa Catarina, 2005

MANZINI-COVRE, Maria de Lourdes. O que é Cidadania. 3aㅗ edição. São Paulo: Editora Brasiliense, Coleção Primeiros Passos n.ำ 20, 1991

WOLKMER, Antonio Carlos. Pluralismo jurídico: fundamentos de uma nova cultura do direito. 3. ed. São Paulo: Alfa-Omega, 2001. 